\title{
Titanium-Anthraquinone Material as a New Design Approach for Electrodes in Aqueous Rechargeable Batteries
}

\author{
Franklin D. R. Maharaj ${ }^{1}\left(\mathbb{D}\right.$ and Michael P. Marshak ${ }^{1,2, * \mathbb{C}}$ \\ 1 Department of Chemistry, University of Colorado, Boulder, CO 80309, USA; franklin.maharaj@colorado.edu \\ 2 Renewable and Sustainable Energy Institute, Boulder, CO 80309, USA \\ * Correspondence: Michael.marshak@colorado.edu
}

Received: 28 February 2020; Accepted: 31 March 2020; Published: 4 April 2020

check for updates

\begin{abstract}
The need for expanded energy storage motivates material development for scalable aqueous secondary batteries. The combination of transition metals with redox-active organics represents a new approach to functional material design. Here, we detail the synthesis of titanium (IV) 1,8-dihydroxyanthraquinone ( $\left.\operatorname{Ti}(1,8-\mathrm{DHAQ})_{2}\right)$ as a novel redox-active material and demonstrate its use as a negative electrode in an aqueous battery. This one-pot synthesis results in amorphous micron-scale particles with titanium binding directly to the carbonyl feature as evidenced by scanning electron microscopy and infrared spectroscopy. When assembled in a coin cell with a lithium manganese oxide positive electrode, the active material can be electrochemically cycled with a charge density of $40 \mathrm{mAh} / \mathrm{g}$ at $1.1 \mathrm{~V}$. This represents a new method of creating simple and scalable electrodes using metal-organic materials for versatile energy storage applications.
\end{abstract}

Keywords: aqueous battery; titanium anode; manganese battery; anthraquinone; metal-organic material

\section{Introduction}

The rising use of variable-output renewable energy in the form of solar and wind power has increased the demand for large- and medium-scale electrical energy storage [1,2]. Lithium-ion batteries are effective for high power and high energy density applications such as small-scale consumer electronics, electric vehicles, and increasingly for short to medium term grid-scale storage [3-6]. Similarly, flow-batteries can provide a compelling engineering framework for grid-scale energy storage [7]. Beyond these technologies, however, there is still significant need for safe and affordable battery technologies designed for the intermediate-scale, 10-100 kWh range, which could provide reliable energy storage for homes and small business. In this space, aqueous batteries are attractive as they are nonflammable and have a low solvent cost. Additionally, their lower energy density compared with lithium-ion is less of a concern in stationary applications [2]. Positive electrode materials including lead oxide [8], manganese oxide [9], and nickel oxide [10-12] have been used as a stable positive electrode material for acidic, neutral, and alkaline electrolytes, respectively. Previous studies have demonstrated the suitability of lithium manganese oxide (LMO) as an effective cathode material in aqueous secondary batteries [13-15] and lithium sulfate has been used in conjunction with LMO electrodes [16] as an electrolyte. Zinc-manganese dioxide primary batteries are manufactured on a global scale [17], and secondary batteries based on similar chemistries show incredible promise for intermediate-scale applications due to the highly scalable positive electrode which can be designed for high cycle life and stability [18-21]. There still, however, remains a compelling need for innovative negative electrode materials to replace zinc, which forms dendrites [22-24] and has been identified as the major contributor to capacity decline in secondary $\mathrm{Zn}-\mathrm{MnO}_{2}$ batteries [25]. 
Organic redox-active materials provide a vast chemical space for potential low-cost negative electrode materials. For example, quinones, which undergo a rapid, two-electron reduction [26,27], have been used recently in aqueous flow batteries in acidic [28], basic [29], and neutral electrolytes. Quinones are also highly tunable, and their derivatives can shift their half-cell potential as a result of functional group [30], $\mathrm{pH}[31,32]$, and coordinating solvent [26,33]. To translate these technologies to traditional battery architectures, the materials must be rendered both insoluble and stable throughout their range of charge states. One approach to immobilize organics is to incorporate them into a polymer backbone $[16,34,35]$. This approach has achieved a long cycle life and material capacity but has potential challenges in adoption due to the synthesis cost and scalability [36].

Another approach for electrode design utilizes the combination of organics with metals to create crystalline battery materials in the form of metal-organic frameworks (MOFs). While MOFs can be designed for conductivity and energy storage [37,38], they are often not conductive over their complete charging range and may suffer from slow intercalation kinetics [36,39,40], making them more attractive for use in capacitors. MOFs often require specialized synthetic procedures requiring high temperatures and pressures, and may be cost inefficient at an industrial level. Some recent approaches have been more successful at cost-effective design by using high surface area carbon $[13,15]$ and $\mathrm{NaTi}_{2}(\mathrm{PO} 4)_{3}[41]$ as electrode materials, but there is still need for new design principles to create safe, scalable battery materials.

Our design approach for new negative electrode materials targets the combination of redox-active organics and transition metals. This is, to our knowledge, the first aqueous battery with a solid electrode comprised of both organic anions and transition metal cations, both of which could be redox-accessible. This approach offers the potential for increased energy density and tunability of electrode materials. Here, we report the synthesis, characterization, and performance of a titanium-anthraquinone material, which represents a broad class of low-cost energy storage materials consisting of metals coordinated by redox-active organics. Ti(1,8-DHAQ $)_{2}$ is synthesized in one step from commodity chemical precursors and can be reversibly cycled around $1.1 \mathrm{~V}$ vs. a manganese oxide positive electrode with a specific capacity over $40 \mathrm{mAh} / \mathrm{g}$.

\section{Materials and Methods}

Titanium isopropoxide (TTIP) and 1,8-dihydroxyanthraquione (1,8-DHAQ) were combined in a one-pot reaction to synthesize Ti(1,8-DHAQ $)_{2}$. Two equivalents $(2.0 \mathrm{mmol}, 0.480 \mathrm{~g})$ of 1,8 -DHAQ (Acros Organics) was added to mesitylene $(5 \mathrm{~mL})$ in a $50 \mathrm{~mL}$ round-bottom flask and heated to $150{ }^{\circ} \mathrm{C}$. The flask was attached to a Schlenk line and was flushed under constant nitrogen. One equivalent $(0.3 \mathrm{~mL}, 1 \mathrm{mmol})$, of titanium(IV) tetraisopropoxide (BeanTown Chemical) was syringed into the reaction mixture, immediately turning the light-orange solution to a dark-red. The reaction was then left on heat for one week at $150{ }^{\circ} \mathrm{C}$ in a short-path distillation apparatus. After cooling to room temperature, the mixture was vacuum filtered, and the resulting black solid was subsequently washed with toluene, followed by methanol, followed by a $\mathrm{pH} 11$ sodium hydroxide solution. The solid product was placed in a sublimation apparatus and heated to $300^{\circ} \mathrm{C}$ under a 15 millitorr vacuum to remove any excess 1,8-DHAQ. The material was characterized by the attenuated total reflectance (ATR) infrared (IR) spectroscopy, field emission scanning electron microscopy (FESEM), energy dispersive X-ray spectroscopy (EDS), and powder X-ray diffraction (XRD). A detailed description of the physical characterization methods for $\operatorname{Ti}(1,8-\mathrm{DHAQ})_{2}$ can be found in the supporting information.

The Ti(1,8-DHAQ) 2 product was tested in a 2032-size coin cell battery. The cell assembly method was adapted from established procedures [42]. Lithium manganese oxide (LMO), polytetrafluoroethyele (PTFE) condensed liquid binder, Super P carbon black conductive powder, and 2032-type coin cell casings were purchased from MTI Corporation. The active material was combined with the conductive powder and PTFE binder in a 6:3:1 ratio. Ten percent by weight $N$-methyl-2-pyrrolidone (NMP) was added to create a slurry, which was ground with a mortar and pestle and spread on a $15 \mathrm{~mm}$ diameter stainless-steel mesh disc (70 threads per inch). This procedure was done for both the Ti(1,8-DHAQ) 2 
and LMO active materials to create a negative and positive electrode. A grade 691 glass microfiber filter (VWR) was cut in a $19 \mathrm{~mm}$ diameter circle and soaked in $0.5 \mathrm{M}$ lithium sulfate to be used as the separator. The electrodes were assembled in a 2032-format coin cell with pH $70.5 \mathrm{M}$ lithium sulfate as electrolyte. The batteries were tested using an 8-channel battery analyzer (MTI). The half-cell electrical impedance spectroscopy (EIS) was performed on a Gamry 1000 potentiostat in a three-electrode cell with a silver/silver chloride reference electrode.

\section{Results and Discussion}

The one-pot synthesis of these metal-anthraquinone materials was based on studies of magnetic moments in metal-quinone complexes [43-47] and descriptions of the synthesis of titanium-hydroxyanthracene covalent metal-organic networks (CMONs) [48-51]. Manganese-bound 1,4-dihydroxyanthraquinone materials have been shown to be redox-active in dimethylsulphoxide [52], and a variety of metals can form chelate polymers with napthazarin [53], as well as a variety of hydroxyquinones [54]. For this work, iron, zinc, manganese, and titanium materials were considered in preliminary research due to production cost and environmental availability [55]. Titanium-based materials often demonstrated insolubility when reduced, and were selected for further study. The strength of titanium-oxygen bonds contributes to the overall stability of titanium-based chelate materials [56]. Titanium has been used as an alkaline flow battery electrolyte when coordinated with catechol [57]; the stability of these compounds under electrochemical cycling indicated that a solid analogue might be used in a solid-electrode battery. Titanium isopropoxide has been used to synthesize $\mathrm{TiO}_{2}$ nanoparticles by sol-gel synthesis [58], and was chosen as a titanium source due to the formation of isopropanol as a side product, which would boil in the high-temperature reaction mixture. These papers influenced the synthesis in this work by implying that multiple quinones may coordinate to metals either as bidentate or monodentate ligands, and by using titanium as a stable metal center for solid metal-organic materials. Based on this literature precedent, we suspect that the hydroxyanthraquinone would coordinate to titanium through the oxygen atoms. Anthraquinone derivatives were similarly chosen for their industrial scalability. 1,8-dihydroxyanthraquinone (1,8-DHAQ), also known as dantron or chrysazin, is readily available commercially as a stimulant laxative.

The resulting material was tested for crystallinity by powder X-ray diffraction (XRD). The resulting diffraction pattern (Supplementary Materials Figure S6) strongly indicates an amorphous molecular structure. The diffraction pattern provides no evidence for crystalline titanium dioxide in the sample, suggesting covalent titanium-anthraquinone linkages. While the amorphous nature of this material cannot be resolved by single-crystal XRD, information about the structure could be determined by electron microscopy, X-ray spectroscopy, and infrared spectroscopy.

The morphological characterization of Ti(1,8-DHAQ $)_{2}$ was performed by field emission scanning electron microscopy (FESEM) and energy-dispersive X-ray spectroscopy (EDS) using a JEOL JSM-7401F. The material is largely comprised of spherical microparticles (Figure 1a). EDS mapping, also shown in Figure 1, provides evidence that the titanium and anthraquinone are dispersed evenly throughout the sample.

Individual points on several samples were selected for quantitative EDS analysis. X-ray spectra for these points were obtained, providing ratios of titanium and oxygen (Supplemental Figures S3 and S4). The mounting tape for material was carbon-based, limiting the use of the carbon in obtaining elemental percentages. The atom percent of titanium and oxygen, respectively, was consistently $11 \% \pm 2 \%$ to $88 \% \pm 2 \%$ across the samples (Supplementary Materials Figure S5 and Table S1). This percentage indicates the ratio of titanium to oxygen to be 1:8. This would represent a ratio of titanium to 1,8-DHAQ of 1:2. This ratio supports evidence that the $\mathrm{Ti}^{4+}$ ion is coordinated to four of the deprotonated hydroxy groups on the 1,8-DHAQ ${ }^{2-}$ species. 
a.

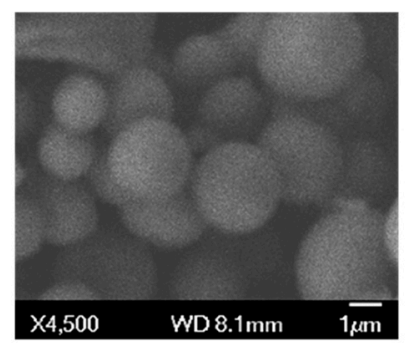

c.

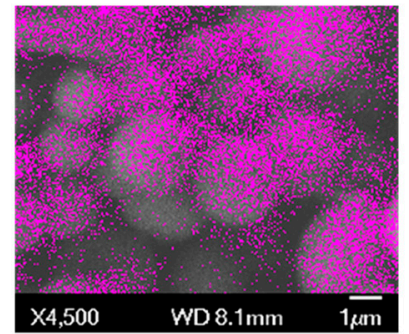

b.

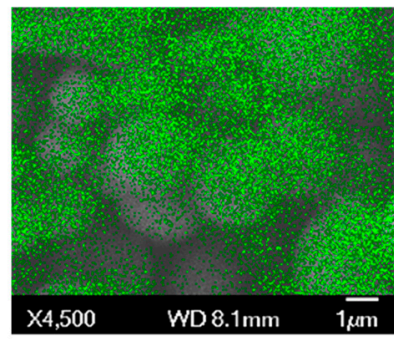

d.

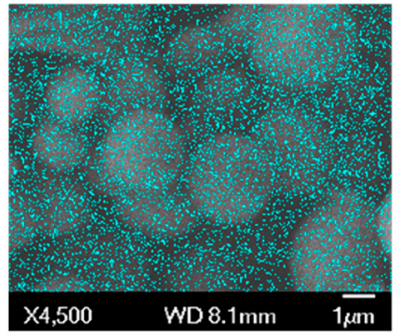

Figure 1. SEM/EDS images of the Ti(1,8-DHAQ) $)_{2}$ microparticles. (a) Background SEM image. (b) EDS mapping of carbon in green. (c) EDS mapping of oxygen in magenta. (d) EDS mapping of titanium in blue.

Attenuated total reflectance (ATR) infrared (IR) spectroscopy provided a method of comparing the bonding between the reactant and product. The Ti(1,8-DHAQ) 2 compounds have a noticeable decrease in the intensity of the carbonyl stretch compared to the 1,8-DHAQ material (Figure 2). The vibrational modes of the 1,8-DHAQ starting material were assigned by density functional theory (DFT) to inform the comparison between the Ti(1,8-DHAQ) 2 and 1,8-DHAQ spectra. Theoretical calculations were performed using the ORCA program package [59,60] along with Avogadro [61,62] to visualize the molecular orbitals and energies. The density functional theory (DFT) was used for all electronic structure calculations, with the BP86 [63-65] functional and the RI-J [66] approximation. The molecule was calculated at the def2-TZVP level of theory $[67,68]$. Specifically, the theoretical IR indicates that the peak around $1620 \mathrm{~cm}^{-1}$ in the 1,8-DHAQ spectrum corresponds to the rocking of the hydrogen atoms bridging between the carbonyl in the 9-position and the hydroxyl groups in the 1- and 8- positions; this peak is weakly associated with the carbonyl stretch in the 10-position. Conversely, the peak at $1670 \mathrm{~cm}^{-1}$ primarily corresponds to the carbonyl stretch in the 10-position, coupled with the rocking hydrogen atoms between the oxygen bound to carbon 9 and the two hydroxyl groups. Based on these assignments, the coordination of the titanium is expected to only slightly mute the intensity of the peak at $1670 \mathrm{~cm}^{-1}$ as the major contribution of the carbonyl stretch in position 10 is unchanged. The $1620 \mathrm{~cm}^{-1}$ peak, however, is expected to decrease much more significantly in the titanium-bound species. These results are consistent with the experimental infrared spectrum of the Ti(1,8-DHAQ $)_{2}$ product. The details for the DFT methods can be found in the Supplemental Materials.

When analyzed together, these characterization techniques inform the structure of the Ti(1,8-DHAQ) 2 product. The sample lacked sharp peaks in the powder XRD and gave no evidence of crystalline $\mathrm{TiO}_{2}$, indicating that the anthraquinone was directly bonded to the titanium as an amorphous structure (Supplementary Materials Figure S1). EDS mapping gave evidence that the component elements of the material were spread through the sample, and sampled EDS spectra indicated an 8:1 atomic ratio of oxygen to titanium. The IR shows a decrease in the hydrogen bonding between the hydroxyl groups. This data suggests that the titanium anthraquinone ratio is $1: 2$, and the $\mathrm{Ti}^{4+}$ is charge balanced by binding to four deprotonated hydroxyl groups of DHAQ, which are able to bridge multiple $\mathrm{Ti}^{4+}$ sites to give an extended solid. A proposed general structure based on these data is given in Figure 3, which implies octahedral coordination about titanium through binding to four hydroxy groups of two adjacent ketones. 
a.

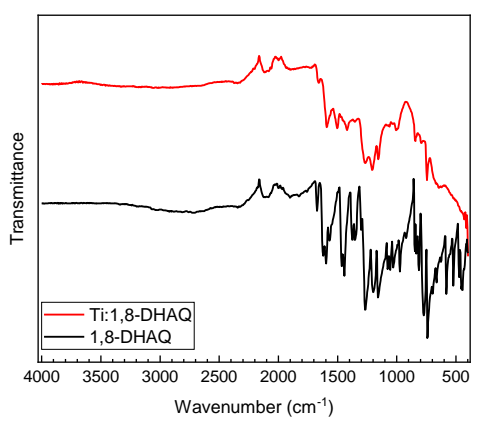

b.

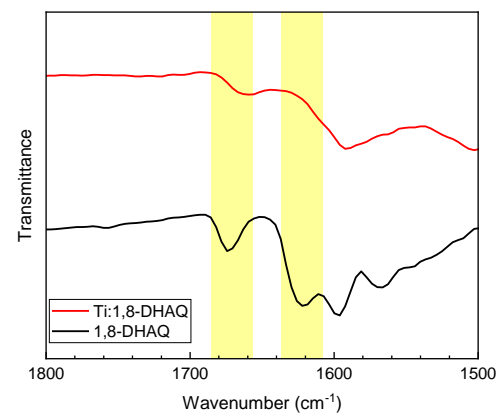

C.

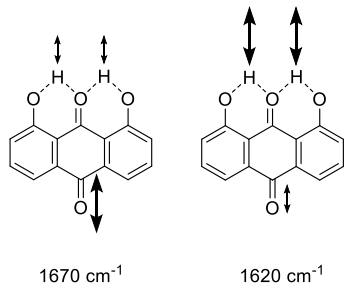

Figure 2. (a) Infrared spectra of $\mathrm{Ti}(1,8-\mathrm{DHAQ})_{2}$ (red) and 1,8-DHAQ starting material (black). (b) Expanded view of the carbonyl stretching bands demonstrating a decrease in the peak at 1670 and $1620 \mathrm{~cm}^{-1}$ upon metal binding. Molecular structures of the 1,8-DHAQ starting material are shown in (c), with the vibrational modes shown with the corresponding energies as determined by density functional theory (DFT) calculations.

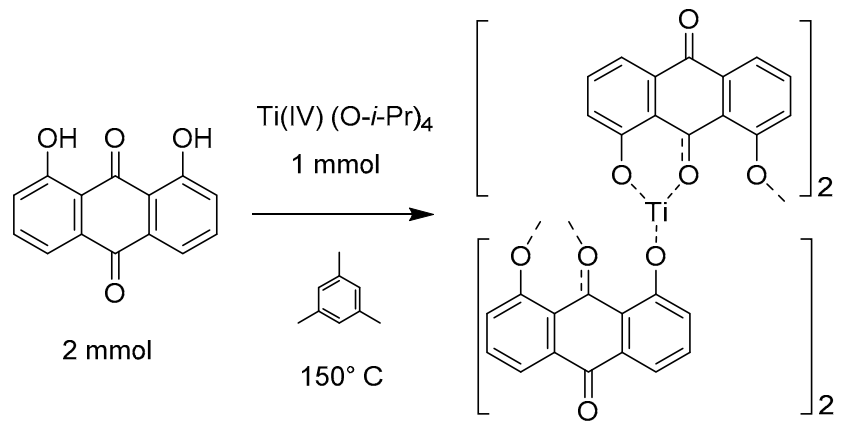

Figure 3. Synthesis and proposed bonding of the $\mathrm{Ti}(1,8-\mathrm{DHAQ})_{2}$ material based on mass ratios and infrared spectroscopy. While the structure does have consistent atomic ratios, $\mathrm{X}$-ray diffraction suggests that the material is not crystalline.

Electrodes prepared from $\mathrm{Ti}(1,8-\mathrm{DHAQ})_{2}$ were tested against a $\mathrm{LiMn}_{2} \mathrm{O}_{4}(\mathrm{LMO})$ positive electrode in an aqueous coin cell. LMO was chosen as a positive electrode material in aqueous electrolyte based on literature precedent and commercial availability. Lithium sulfate was chosen as an electrolyte in part due to the poor performance of aqueous sodium-based electrolytes with the LMO electrode [69]. The battery was charged and discharged to test capacity and stability. LMO $\mid \mathrm{Ti}(1,8-\mathrm{DHAQ})_{2}$ batteries were charged and discharged with a C-rate of C/2.5, as shown in Figure 4a and produced a coulombic efficiency of $89 \%$. The resulting nominal voltage of the battery is approximately $1.1 \mathrm{~V}$.

Battery capacity was significantly influenced by the charge and discharge rate (Figure 4c). The batteries gave the highest capacity when charged and discharged at a rate below $\mathrm{C} / 4$. This suggests that there are kinetic limitations of the system, either in electron transfer or in ion migration for charge balance. To investigate the battery cycle life, $\mathrm{LMO} \mid \mathrm{Ti}(1,8-\mathrm{DHAQ})_{2}$ batteries were cycled for 100 cycles (Figure $4 \mathrm{~b}$ ) at $26 \mathrm{~mA} / \mathrm{g}$, corresponding to a C-rate of approximately 1.75 . There was significant decrease in capacity over repeated cycling. The energy efficiency remained stable around $60 \%$, typical of an aqueous solid-electrode battery [70].

The charge transfer resistance of the Ti(1,8-DHAQ $)_{2}$ material in a three-electrode system was investigated by electrical impedance spectroscopy (EIS). The resulting data, shown on a Nyquist plot in Figure 4d, was fit to an equivalent circuit for a three-electrode cell [71,72] and the component values were calculated by the Nelder-Mead method [73]. The high frequency circuit elements exhibited a capacitance of $90 \times 10^{-6} \mathrm{~F}$ from the constant-phase element [74]. This capacitance is indicative of an electron-exchange reaction [75] and, with the value of the resistor element, indicates a charge-transfer process with a real resistance of $14 \mathrm{~m} \Omega \mathrm{g}$ at ambient temperature $\left(22^{\circ} \mathrm{C}\right)$. At this 
temperature, $\mathrm{Ti}(1,8 \text {-DHAQ })_{2}$ exhibits a higher charge-transfer conductivity than the metal-hydride negative electrodes used in nickel-metal hydride batteries [16,76]

a.

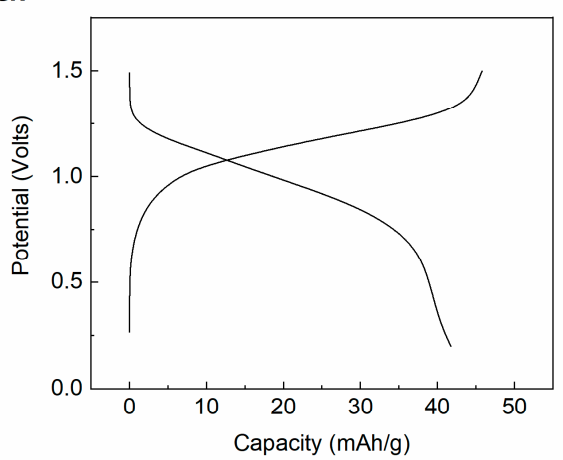

C.

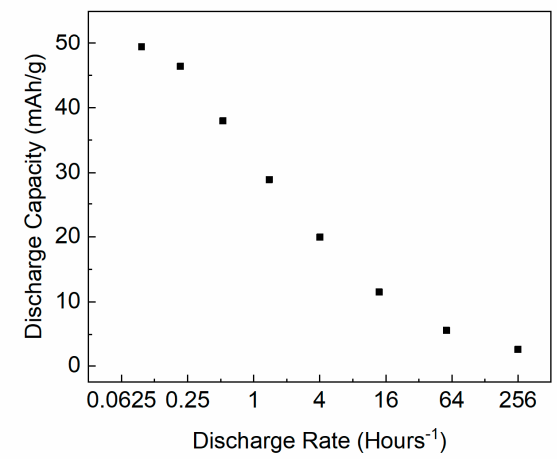

b.

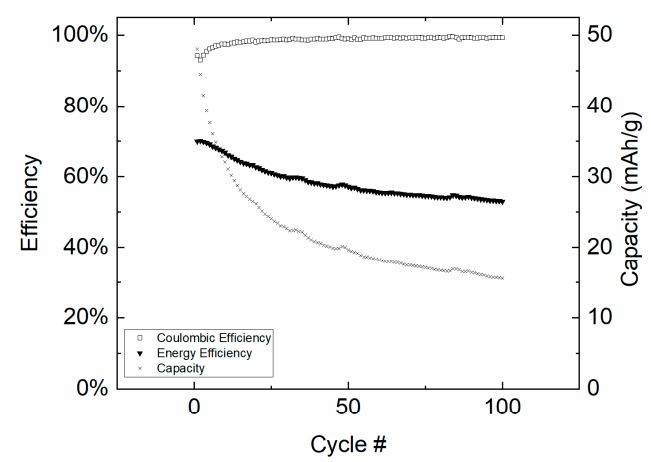

d.

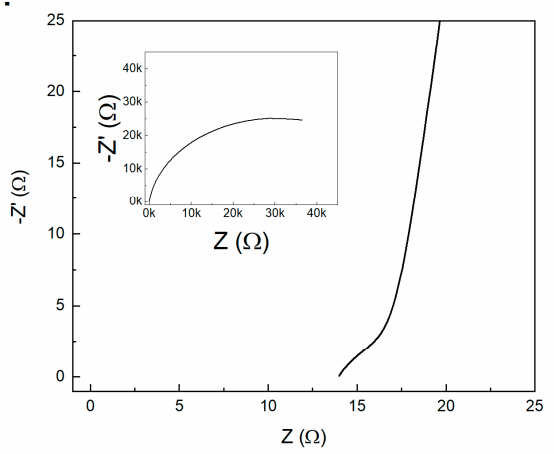

Figure 4. (a) Charge/discharge cycle of a complete LMO | Ti(1,8-DHAQ) 2 battery at a specific current of $7.25 \mathrm{~mA} / \mathrm{g}$. (b) Repeated cycling indicating a significant drop in capacity over time despite current efficiency remaining high. (c) Discharge capacity as a function of discharge rate for a complete coin cell. (d) A Nyquist plot of $\mathrm{Ti}(1,8-\mathrm{DHAQ})_{2}$ vs. $\mathrm{Ag} / \mathrm{AgCl}$ with equivalent circuit elements in supplemental information Table S3.

The Ti(1,8-DHAQ $)_{2}$ system unfortunately displays a decline in capacity over repeated charging. Although the Ti(1,8-DHAQ $)_{2}$ batteries are also charged above the thermodynamic voltage window of water, $1.23 \mathrm{~V}$, these high voltages still result in highly stable batteries as nickel metal-hydride batteries (1.4 V nominal voltage) and lead acid batteries (2 V nominal voltage). Disassembled batteries showed no visible dissolution of the $\operatorname{Ti}(1,8-\mathrm{DHAQ})_{2}$ material and no significant deviation from neutral $\mathrm{pH}$ even after repeated cycling - which suggests that water splitting is not occurring as a decomposition pathway. The Ti(1,8-DHAQ $)_{2}$ as prepared did not dissolve in a $\mathrm{pH}$ range of $4-10$, but the reactivity of the material after repeated charging remains unknown, and hydronium or hydroxide ions may react with the reduced $\operatorname{Ti}(1,8-\mathrm{DHAQ})_{2}$ material. The general morphological structure at the micron scale of $\mathrm{Ti}\left(1,8\right.$-DHAQ) ${ }_{2}$ also remained after charging (Supplementary Materials Figure S6), and the ratio of titanium to oxygen by EDS remained 1:8. Titanium catechol systems display robust stability under electrochemical strain $[77,78]$ and are chemically similar to the structures synthesized in this work. For these reasons, we suspect that the degradation of capacity over time is most likely due to a reaction of the quinone under repeated electrochemical stress. Anthraquinone-based redox mediators have been shown to decompose to anthrone complexes when repeatedly reduced and oxidized [79]. This proposed degradation mechanism would alter the structure of the species and inhibit electrochemical reversibility, but does not necessarily lead to dissolution.

The conduction mechanism in amorphous coordination polymers more closely resembles a localized model involving tunneling rather than a solid band model [80,81]. Generally, for a nonintercalating 
electrode, the electronic resistance of the electrode is negligible compared to the ionic transport resistance of the electrolyte [82]. In recent years, the investigation of electrical conductivity in metal-chelate polymers have largely focused on crystalline MOFs [80] or extended metal-catecholates [83] rather than amorphous materials. Unlike crystalline MOFs, amorphous materials can be less regular in structure due to variations in laboratory and environmental conditions [84]. This allows for the optimization of parameters such as tortuosity and porosity for high power applications. For amorphous particulate redox materials, these parameters can be tuned by modifying the binder [85], substrate [86], and deposition method [87].

One advantage of this approach is the potential redox activity of both the linker and the metal. If both the $\mathrm{Ti}^{3+/ 4+}$ couple and the $\mathrm{AQ}^{2-/ 4-}$ couple were accessed, the titanium anthraquinone material as proposed in Figure 3 would result in a theoretical capacity of $255 \mathrm{mAh} / \mathrm{g}$. The batteries tested indicated significantly lower capacity than this, however, likely due to limitations in ionic conductivity through the material for charge balance during charging and discharging. While this material trades chemical stability for low material and production cost, it has a high potential for scalability due to inexpensive materials and solvents. The approach used in this synthesis is general, and other electrode materials might be made using a similar method. The degradation in capacity may be mitigated by the selection of different redox-active organic, and they may produce similar electrochemically active compounds when combined with metal linkers.

\section{Conclusions}

We detail the synthesis of titanium(IV) 1,8-dihydroxyanthraquinone and test the electrochemical activity in a coin cell. This material can be charged and discharged versus a lithium manganese oxide positive electrode. The use of transition metals to link redox-active organics is a novel approach that can provide high theoretical capacity. This is the first such metal-anthraquinone material used in secondary batteries. Further research may work at preventing the battery capacity deterioration over repeated cycling. This new material shows promise in the development of scalable aqueous batteries.

Supplementary Materials: Full Supplemental Materials are available online at http://www.mdpi.com/1996-1073/ 13/7/1722/s1. Figure S1: Powder XRD of the Ti(1,8-DHAQ) 2 material; Figure S2: FESEM images with EDS mapping; Figure S3: FESEM images of points taken; Figure S4: FESEM of second sample of Ti(1,8-DHAQ) 2 ; Figure S5: EDS point spectra; Figure S6: FESEM of Ti(1,8-DHAQ $)_{2}$ after charging; Figure S7: Theoretical IR of 1,8-DHAQ; Figure S8: Equivalent circuit used to model Ti(1,8-DHAQ $)_{2}$; Figure S9: Bode plot of Ti(1,8-DHAQ) ${ }_{2}$ with equivalent circuit fit. Table S1: Ratios from EDS; Table S2: Cartesian coordinates from DFT; Table S3: EIS equivalent circuit component parameters.

Author Contributions: Investigation, F.D.R.M.; analysis, F.D.R.M.; writing, F.D.R.M.; supervision, M.P.M. All authors have read and agreed to the published version of the manuscript.

Funding: The authors thank CU Boulder for start-up research funds.

Acknowledgments: We thank the University of Colorado and the Renewable and Sustainable Energy Institute. We also thank Greg Dwulet, Tomoko Borsa, and the Colorado Shared Instrumentation in Nanofabrication and Characterization for use of their instrumentation.

Conflicts of Interest: The authors declare no conflict of interest.

\section{References}

1. Goodenough, J.B.; Manthiram, A. A perspective on electrical energy storage. MRS Commun. 2014, 4, 135-142. [CrossRef]

2. Dunn, B.; Kamath, H.; Tarascon, J.-M. Electrical Energy Storage for the Grid: A Battery of Choices. Science 2011, 334, 928-935. [CrossRef] [PubMed]

3. Pollet, B.G.; Staffell, I.; Shang, J.L. Current status of hybrid, battery and fuel cell electric vehicles: From electrochemistry to market prospects. Electrochim. Acta 2012, 84, 235-249. [CrossRef]

4. Blomgren, G.E. The Development and Future of Lithium Ion Batteries. J. Electrochem. Soc. 2017, 164, A5019-A5025. [CrossRef] 
5. Mauger, A.; Julien, C.M.; Paolella, A.; Armand, M.; Zaghib, K. A comprehensive review of lithium salts and beyond for rechargeable batteries: Progress and perspectives. Mater. Sci. Eng. R Rep. 2018, 134, 1-21. [CrossRef]

6. Mauger, A.; Julien, C.M.; Paolella, A.; Armand, M.; Zaghib, K. Building Better Batteries in the Solid State: A Review. Materials 2019, 12, 3892. [CrossRef]

7. Soloveichik, G.L. Flow Batteries: Current Status and Trends. Chem. Rev. 2015, 115, 11533-11558. [CrossRef]

8. Linden, D.; Reddy, T.B. Handbook of Batteries; McGraw-Hill: New York, NY, USA, 2002; ISBN 978-0-07-135978-8.

9. Hem, J.D. Redox processes at surfaces of manganese oxide and their effects on aqueous metal ions. Chem. Geol. 1978, 21, 199-218. [CrossRef]

10. Chakkaravarthy, C.; Periasamy, P.; Jegannathan, S.; Vasu, K.I. The nickel/iron battery. J. Power Source 1991, 35 , 21-35. [CrossRef]

11. Majeau-Bettez, G.; Hawkins, T.R.; Strømman, A.H. Life Cycle Environmental Assessment of Lithium-Ion and Nickel Metal Hydride Batteries for Plug-In Hybrid and Battery Electric Vehicles. Environ. Sci. Technol. 2011, 45, 4548-4554. [CrossRef]

12. Jayalakshmi, N.; Muralidharan, V.S. Developmental studies on porous iron electrodes for the nickel iron cell. J. Power Sources 1990, 32, 341-351. [CrossRef]

13. Whitacre, J.F.; Wiley, T.; Shanbhag, S.; Wenzhuo, Y.; Mohamed, A.; Chun, S.E.; Weber, E.; Blackwood, D.; Lynch-Bell, E.; Gulakowski, J.; et al. An aqueous electrolyte, sodium ion functional, large format energy storage device for stationary applications. J. Power Sources 2012, 213, 255-264. [CrossRef]

14. Whitacre, J.F.; Tevar, A.; Sharma, S. Na4Mn9O18 as a positive electrode material for an aqueous electrolyte sodium-ion energy storage device. Electrochem. Commun. 2010, 12, 463-466. [CrossRef]

15. Tevar, A.D.; Whitacre, J.F. Relating Synthesis Conditions and Electrochemical Performance for the Sodium Intercalation Compound Na4Mn9O18 in Aqueous Electrolyte. J. Electrochem. Soc. 2010, 157, A870-A875. [CrossRef]

16. Liang, Y.; Jing, Y.; Gheytani, S.; Lee, K.-Y.; Liu, P.; Facchetti, A.; Yao, Y. Universal quinone electrodes for long cycle life aqueous rechargeable batteries. Nat. Mater. 2017, 16, 841-848. [CrossRef] [PubMed]

17. Brito, P.S.D.; Patrício, S.; Rodrigues, L.F.; Sequeira, C.A.C. Electrodeposition of Zn-Mn alloys from recycling Zn-MnO2 batteries solutions. Surf. Coat. Technol. 2012, 206, 3036-3047. [CrossRef]

18. Kordesch, K.; Gsellmann, J.; Peri, M.; Tomantschger, K.; Chemelli, R. The rechargeability of manganese dioxide in alkaline electrolyte. Electrochim. Acta 1981, 26, 1495-1504. [CrossRef]

19. Kordesh, K.; Weissenbacher, M. Rechargeable alkaline manganese dioxide/zinc batteries. J. Power Sources 1994, 51, 61-78. [CrossRef]

20. Shen, Y.; Kordesch, K. The mechanism of capacity fade of rechargeable alkaline manganese dioxide zinc cells. J. Power Sources 2000, 87, 162-166. [CrossRef]

21. Bailey, M.R.; Donne, S.W. Structural effects on the cyclability of the alkaline $\gamma-\mathrm{MnO} 2$ electrode. Electrochim. Acta 2011, 56, 5037-5045. [CrossRef]

22. Popov, K.I.; Pavlović, M.G.; Spasojević, M.D.; Nakić, V.M. The critical overpotential for zinc dendrite formation. J. Appl. Electrochem. 1979, 9, 533-536. [CrossRef]

23. Lee, J.-S.; Kim, S.T.; Cao, R.; Choi, N.-S.; Liu, M.; Lee, K.T.; Cho, J. Metal-Air Batteries with High Energy Density: Li-Air versus Zn-Air. Adv. Energy Mater. 2011, 1, 34-50. [CrossRef]

24. Bass, K.; Mitchell, P.J.; Wilcox, G.D.; Smith, J. Methods for the reduction of shape change and dendritic growth in zinc-based secondary cells. J. Power Sources 1991, 35, 333-351. [CrossRef]

25. Minakshi, M.; Ionescu, M. Anodic behavior of zinc in Zn-MnO2 battery using ERDA technique. Int. J. Hydrogen Energy 2010, 35, 7618-7622. [CrossRef]

26. Quan, M.; Sanchez, D.; Wasylkiw, M.F.; Smith, D.K. Voltammetry of Quinones in Unbuffered Aqueous Solution: Reassessing the Roles of Proton Transfer and Hydrogen Bonding in the Aqueous Electrochemistry of Quinones. J. Am. Chem. Soc. 2007, 129, 12847-12856. [CrossRef]

27. Van Dijk, E.H.; Myles, D.J.T.; van der Veen, M.H.; Hummelen, J.C. Synthesis and Properties of an Anthraquinone-Based Redox Switch for Molecular Electronics. Org. Lett. 2006, 8, 2333-2336. [CrossRef]

28. Huskinson, B.; Marshak, M.P.; Suh, C.; Er, S.; Gerhardt, M.R.; Galvin, C.J.; Chen, X.; Aspuru-Guzik, A.; Gordon, R.G.; Aziz, M.J. A metal-free organic-inorganic aqueous flow battery. Nature 2014, 505, 195-198. [CrossRef] 
29. Lin, K.; Chen, Q.; Gerhardt, M.R.; Tong, L.; Kim, S.B.; Eisenach, L.; Valle, A.W.; Hardee, D.; Gordon, R.G.; Aziz, M.J.; et al. Alkaline quinone flow battery. Science 2015, 349, 1529-1532. [CrossRef]

30. Bachman, J.E.; Curtiss, L.A.; Assary, R.S. Investigation of the Redox Chemistry of Anthraquinone Derivatives Using Density Functional Theory. J. Phys. Chem. A 2014, 118, 8852-8860. [CrossRef]

31. Wildgoose, G.G.; Pandurangappa, M.; Lawrence, N.S.; Jiang, L.; Jones, T.G.J.; Compton, R.G. Anthraquinone-derivatised carbon powder: Reagentless voltammetric pH electrodes. Talanta 2003, 60, 887-893. [CrossRef]

32. Lafitte, V.G.H.; Wang, W.; Yashina, A.S.; Lawrence, N.S. Anthraquinone-ferrocene film electrodes: Utility in pH and oxygen sensing. Electrochem. Commun. 2008, 10, 1831-1834. [CrossRef]

33. Peover, M.E. A polarographic investigation into the redox behaviour of quinones: The roles of electron affinity and solvent. J. Chem. Soc. 1962, 4540-4549. [CrossRef]

34. Dong, X.; Chen, L.; Liu, J.; Haller, S.; Wang, Y.; Xia, Y. Environmentally-friendly aqueous Li (or Na)-ion battery with fast electrode kinetics and super-long life. Sci. Adv. 2016, 2, e1501038. [CrossRef] [PubMed]

35. Mauger, A.; Julien, C.; Paolella, A.; Armand, M.; Zaghib, K. Recent Progress on Organic Electrodes Materials for Rechargeable Batteries and Supercapacitors. Materials 2019, 12, 1770. [CrossRef] [PubMed]

36. Zhao, C.; Zheng, W. A Review for Aqueous Electrochemical Supercapacitors. Front. Energy Res. 2015, 3, 23. [CrossRef]

37. Parker, J.F.; Chervin, C.N.; Pala, I.R.; Machler, M.; Burz, M.F.; Long, J.W.; Rolison, D.R. Rechargeable nickel-3D zinc batteries: An energy-dense, safer alternative to lithium-ion. Science 2017, 356, 415-418. [CrossRef]

38. Duhović, S.; Dincă, M. Synthesis and Electrical Properties of Covalent Organic Frameworks with Heavy Chalcogens. Chem. Mater. 2015, 27, 5487-5490. [CrossRef]

39. Choi, K.M.; Jeong, H.M.; Park, J.H.; Zhang, Y.-B.; Kang, J.K.; Yaghi, O.M. Supercapacitors of Nanocrystalline Metal-Organic Frameworks. ACS Nano 2014, 8, 7451-7457. [CrossRef]

40. Sheberla, D.; Bachman, J.C.; Elias, J.S.; Sun, C.-J.; Shao-Horn, Y.; Dincă, M. Conductive MOF electrodes for stable supercapacitors with high areal capacitance. Nat. Mater. 2017, 16, 220-224. [CrossRef]

41. Whitacre, J.F.; Shanbhag, S.; Mohamed, A.; Polonsky, A.; Carlisle, K.; Gulakowski, J.; Wu, W.; Smith, C.; Cooney, L.; Blackwood, D.; et al. A Polyionic, Large-Format Energy Storage Device Using an Aqueous Electrolyte and Thick-Format Composite NaTi2(PO4)3/Activated Carbon Negative Electrodes. Energy Technol. 2015, 3, 20-31. [CrossRef]

42. Kayyar, A.; Huang, J.; Samiee, M.; Luo, J. Construction and Testing of Coin Cells of Lithium Ion Batteries. J. Vis. Exp. 2012, 66, e4104. [CrossRef] [PubMed]

43. Pierpont, C.G.; Downs, H.H.; Rukavina, T.G. Neutral tris(o-benzoquinone) complexes of chromium, molybdenum, and tungsten. J. Am. Chem. Soc. 1974, 96, 5573-5574. [CrossRef]

44. Cerezo, J.; Requena, A.; Zúñiga, J.; Piernas, M.J.; Santana, M.D.; Pérez, J.; García, L. Structural and magnetic characterization of [Ni2(tren)2(C6O4Cl2)](BPh4)2 and [Cu2(Me5dien)2(C6O4Cl2)](BPh4)2. Magnetic exchange interactions propagated by the dianions of 2,5-dihydroxy-1,4-benzoquinones. Inorg. Chem. 1977, 16, 2367-2376.

45. Pierpont, C.G.; Francesconi, L.C.; Hendrickson, D.N. Magnetic exchange interactions in binuclear transition-metal complexes. Dianions of 5,8-dihydroxy-1,4-naphthoquinone, 1,4-dihydroxy-9,10-anthraquinone, and 1,5-dihydroxy-9,10-anthraquinone as bridging ligands in copper(II) and nickel(II) complexes. Inorg. Chem. 1978, 17, 3470-3477. [CrossRef]

46. Pierpont, C.G.; Buchanan, R.M. Transition metal complexes of o-benzoquinone, o-semiquinone, and catecholate ligands. Coord. Chem. Rev. 1981, 38, 45-87. [CrossRef]

47. Buchanan, R.M.; Kessel, S.L.; Downs, H.H.; Pierpont, C.G.; Hendrickson, D.N. Structural and magnetic properties of tris(o-semiquinone) complexes of iron(III) and chromium(III). J. Am. Chem. Soc. 1978, 100, 7894-7900. [CrossRef]

48. Vaid, T.P.; Lobkovsky, E.B.; Wolczanski, P.T. Covalent 3- and 2-Dimensional Titanium-Quinone Networks. J. Am. Chem. Soc. 1997, 119, 8742-8743. [CrossRef]

49. Vaid, T.P.; Tanski, J.M.; Pette, J.M.; Lobkovsky, E.B.; Wolczanski, P.T. Covalent Three-Dimensional Titanium(IV)-Aryloxide Networks. Inorg. Chem. 1999, 38, 3394-3405. [CrossRef]

50. Tanski, J.M.; Vaid, T.P.; Lobkovsky, E.B.; Wolczanski, P.T. Covalent Metal-Organic Networks: Pyridines Induce 2-Dimensional Oligomerization of ( $\mu$-OC6H4O)2Mpy2 $(\mathrm{M}=\mathrm{Ti}, \mathrm{V}, \mathrm{Zr})$. Inorg. Chem. 2000, 39, 4756-4765. [CrossRef] 
51. Tanski, J.M.; Lobkovsky, E.B.; Wolczanski, P. Covalent Titanium(IV)-Aryloxide Network Materials: 4,4'-Biphenoxide 3D and Polyphenolic 2D Motifs. J. Solid State Chem. 2000, 152, 130-140. [CrossRef]

52. Bodini, M.E.; Arancibia, V. Redox chemistry of 1,4-dihydroxy-9,10-anthraquinone (quinizarine) and its manganese(II) complexes in dimethylsulphoxide. Polyhedron 1991, 10, 1929-1937. [CrossRef]

53. Bottei, R.S.; Gerace, P.L. Preparation and thermal stabilities of some metal chelate polymers of naphthazarin. J. Inorg. Nucl. Chem. 1961, 23, 245-251. [CrossRef]

54. Coble, H.D.; Holtzclaw, H.F. Chelate polymers of copper(II) with various dihydroxyquinoid ligands. J. Inorg. Nucl. Chem. 1974, 36, 1049-1053. [CrossRef]

55. Vesborg, P.C.K.; Jaramillo, T.F. Addressing the terawatt challenge: Scalability in the supply of chemical elements for renewable energy. RSC Adv. 2012, 2, 7933-7947. [CrossRef]

56. Nguyen, H.L. The chemistry of titanium-based metal-organic frameworks. New J. Chem. 2017, 41, 14030-14043. [CrossRef]

57. Esswein, A.J.; Goeltz, J.; King, E.R.; Reece, S.Y.; Amadeo, D. Aqueous Redox Flow Batteries Comprising Metal Ligand Coordination Compounds. U.S. Patent Application No. 8,753,761, 17 June 2014.

58. Frantz, C.; Lauria, A.V.; Manzano, C.; Guerra-Nuñez, C.; Niederberger, M.; Storrer, C.; Michler, J.; Philippe, L. Nonaqueous Sol-Gel Synthesis of Anatase Nanoparticles and Their Electrophoretic Deposition in Porous Alumina. Langmuir 2017, 33, 12404-12418. [CrossRef]

59. Neese, F. The ORCA program system. Wiley Interdiscip. Rev. Comput. Mol. Sci. 2012, 2, 73-78. [CrossRef]

60. Neese, F. Software update: The ORCA program system, version 4.0: Software update. WIREs Comput. Mol. Sci. 2018, 8, e1327. [CrossRef]

61. Avogadro: An Open-Source Molecular Builder and Visualization Tool. Version 1.20. Available online: https://avogadro.cc/ (accessed on 11 July 2019).

62. Hanwell, M.D.; Curtis, D.E.; Lonie, D.C.; Vandermeersch, T.; Zurek, E.; Hutchison, G.R. Avogadro: An advanced semantic chemical editor, visualization, and analysis platform. J. Cheminf. 2012, 4, 17. [CrossRef]

63. Perdew, J.P. Density-functional approximation for the correlation energy of the inhomogeneous electron gas. Phys. Rev. B 1986, 33, 8822-8824. [CrossRef]

64. Perdew, J.P. Erratum: Density-functional approximation for the correlation energy of the inhomogeneous electron gas. Phys. Rev. B 1986, 34, 7406. [CrossRef]

65. Becke, A.D. Density-functional exchange-energy approximation with correct asymptotic behavior. Phys. Rev. A 1988, 38, 3098-3100. [CrossRef] [PubMed]

66. Neese, F. An improvement of the resolution of the identity approximation for the formation of the Coulomb matrix. J. Comput. Chem. 2003, 24, 1740-1747. [CrossRef] [PubMed]

67. Weigend, F. Accurate Coulomb-fitting basis sets for H to Rn. Phys. Chem. Chem. Phys. 2006, 8, 1057. [CrossRef]

68. Weigend, F.; Ahlrichs, R. Balanced basis sets of split valence, triple zeta valence and quadruple zeta valence quality for $\mathrm{H}$ to Rn: Design and assessment of accuracy. Phys. Chem. Chem. Phys. 2005, 7, 3297. [CrossRef]

69. Whitacre, J.F.; Shanbhag, S.; Mohamed, A.; Polonsky, A.; Carlisle, K.; Gulakowski, J.; Wu, W.; Smith, C.; Cooney, L.; Blackwood, D.; et al. Corrigendum: A Polyionic, Large-Format Energy Storage Device Using an Aqueous Electrolyte and Thick-Format Composite NaTi2(PO4)3/Activated Carbon Negative Electrodes. Energy Technol. 2015, 3, 796-798. [CrossRef]

70. Fetcenko, M.A.; Ovshinsky, S.R.; Reichman, B.; Young, K.; Fierro, C.; Koch, J.; Zallen, A.; Mays, W.; Ouchi, T. Recent advances in NiMH battery technology. J. Power Sources 2007, 165, 544-551. [CrossRef]

71. Bisquert, J.; Garcia-Belmonte, G.; Fabregat-Santiago, F.; Ferriols, N.S.; Bogdanoff, P.; Pereira, E.C. Doubling Exponent Models for the Analysis of Porous Film Electrodes by Impedance. Relaxation of TiO2 Nanoporous in Aqueous Solution. J. Phys. Chem. B 2000, 104, 2287-2298. [CrossRef]

72. Bard, A.J.; Faulkner, L.R. Electrochemical Methods: Fundamentals and Applications, 2nd ed.; Wiley: New York, NY, USA, 2000; ISBN 978-0-471-04372-0.

73. Nelder, J.A.; Mead, R. A Simplex Method for Function Minimization. Comput. J. 1965, 7, 308-313. [CrossRef]

74. Hsu, C.H.; Mansfeld, F. Concerning the Conversion of the Constant Phase Element Parameter Y0 into a Capacitance. Corrosion 2001, 57, 747-748. [CrossRef]

75. Irvine, J.T.S.; Sinclair, D.C.; West, A.R. Electroceramics: Characterization by Impedance Spectroscopy. Adv. Mater. 1990, 2, 132-138. [CrossRef] 
76. Senoh, H.; Hara, Y.; Inoue, H.; Iwakura, C. Charge efficiency of misch metal-based hydrogen storage alloy electrodes at relatively low temperatures. Electrochim. Acta 2001, 46, 967-971. [CrossRef]

77. Borgias, B.A.; Cooper, S.R.; Koh, Y.B.; Raymond, K.N. Synthetic, structural, and physical studies of titanium complexes of catechol and 3,5-di-tert-butylcatechol. Inorg. Chem. 1984, 23, 1009-1016. [CrossRef]

78. Bazhenova, T.A.; Kovaleva, N.V.; Shilov, G.V.; Petrova, G.N.; Kuznetsov, D.A. A Family of Titanium Complexes with Catechol Ligands: Structural Investigation and Catalytic Application. Eur. J. Inorg. Chem. 2016, 2016, 5215-5221. [CrossRef]

79. Goulet, M.-A.; Tong, L.; Pollack, D.A.; Tabor, D.P.; Odom, S.A.; Aspuru-Guzik, A.; Kwan, E.E.; Gordon, R.G.; Aziz, M.J. Extending the Lifetime of Organic Flow Batteries via Redox State Management. J. Am. Chem. Soc. 2019, 141, 8014-8019. [CrossRef] [PubMed]

80. Givaja, G.; Amo-Ochoa, P.; Gómez-García, C.J.; Zamora, F. Electrical conductive coordination polymers. Chem. Soc. Rev. 2011, 41, 115-147. [CrossRef]

81. Bellitto, C.; Dessy, G.; Fares, V. Synthesis, x-ray crystal structure, and chemical and physical properties of the new linear-chain mixed-valence complex (.mu.-iodo)tetrakis(dithioacetato)dinickel, Ni2(CH3CS2)4I, and $\mathrm{x}$-ray crystal structure of the precursor tetrakis(dithioacetato)dinickel(II), Ni2(CH3CS2). Inorg. Chem. 1985, $24,2815-2820$.

82. Landesfeind, J.; Ebner, M.; Eldiven, A.; Wood, V.; Gasteiger, H.A. Tortuosity of Battery Electrodes: Validation of Impedance-Derived Values and Critical Comparison with 3D Tomography. J. Electrochem. Soc. 2018, 165, A469-A476. [CrossRef]

83. Hmadeh, M.; Lu, Z.; Liu, Z.; Gándara, F.; Furukawa, H.; Wan, S.; Augustyn, V.; Chang, R.; Liao, L.; Zhou, F.; et al. New Porous Crystals of Extended Metal-Catecholates. Chem. Mater. 2012, 24, 3511-3513. [CrossRef]

84. Kulasinski, K.; Guyer, R.A. Quantification of Nanopore Networks: Application to Amorphous Polymers. J. Phys. Chem. C 2016, 120, 28144-28151. [CrossRef]

85. Landesfeind, J.; Eldiven, A.; Gasteiger, H.A. Influence of the Binder on Lithium Ion Battery Electrode Tortuosity and Performance. J. Electrochem. Soc. 2018, 165, A1122-A1128. [CrossRef]

86. Zhang, Y.; Luo, W.; Wang, C.; Li, Y.; Chen, C.; Song, J.; Dai, J.; Hitz, E.M.; Xu, S.; Yang, C.; et al. High-capacity, low-tortuosity, and channel-guided lithium metal anode. Proc. Natl. Acad. Sci. USA 2017, 114, 3584-3589. [CrossRef] [PubMed]

87. Glasscott, M.W.; Pendergast, A.D.; Choudhury, M.H.; Dick, J.E. Advanced Characterization Techniques for Evaluating Porosity, Nanopore Tortuosity, and Electrical Connectivity at the Single-Nanoparticle Level. ACS Appl. Nano Mater. 2019, 2, 819-830. [CrossRef] 